EDITOR'S

CHOICE

PAPER

\title{
Neurotrauma and the rule of rescue
}

\author{
S Honeybul, ${ }^{1}$ G R Gillett, ${ }^{2,3}$ K M Ho, ${ }^{4}$ C R P Lind ${ }^{1,5}$
}

${ }^{1}$ Department of Neurosurgery, Sir Charles Gairdner Hospital and Royal Perth Hospital, Perth, Western Australia, Australia

2Dunedin Hospital, University of Otago, Dunedin, New Zealand ${ }^{3}$ Otago Bioethics Centre, University of Otago, Dunedin, New Zealand

${ }^{4}$ Department of Intensive Care Medicine and School of

Population Health, University of Western Australia, Perth, Western Australia, Australia

${ }^{5}$ School of Surgery, University of Western Australia, Perth, Western Australia, Australia

\section{Correspondence to}

S Honeybul, Sir Charles Gairdner Hospital, Perth, WA 6009,

Australia; stephen.honeybul@ health.wa.gov.au

Received 10 July 2011 Revised 22 July 2011 Accepted 26 July 2011 Published Online First 24 September 2011

\section{ABSTRACT}

The rule of rescue describes the powerful human proclivity to rescue identified endangered lives, regardless of cost or risk. Deciding whether or not to perform a decompressive craniectomy as a life-saving or 'rescue' procedure for a young person with a severe traumatic brain injury provides a good example of the ethical tensions that occur in these situations. Unfortunately, there comes a point when the primary brain injury is so severe that if the patient survives they are likely to remain severely disabled and fully dependent. The health resource implications of this outcome are significant. By using a web-based outcome prediction model this study compares the long-term outcome and designation of two groups of patients. One group had a very severe injury as adjudged by the model and the other group a less severe injury. At 18 month follow-up there were significant differences in outcome and healthcare requirements. This raises important ethical issues when considering life-saving but non-restorative surgical intervention. The discussion about realistic outcome cannot be dichotomised into simply life or death so that the outcome for the patient must enter the equation. As in other 'rescue situations', the utility of the procedure cannot be rationalised on a mere cost-benefit analysis. A compromise has to be reached to determine at what point either the likely outcome would be unacceptable to the person on whom the procedure is being performed or the social utility gained from the rule of rescue intervention fails to justify the utilitarian value and justice of equitable resource allocation.

\section{INTRODUCTION}

In all areas of medicine there comes a time when an illness or injury may be so severe that medical or surgical intervention will not only fail to benefit the patient but will also place an undue resource burden on the community. Deciding whether or not to perform a decompressive craniectomy as a life-saving or 'rescue' procedure for a young person with a severe traumatic brain injury provides a good example of the ethical tension that can occur in these situations.

The procedure is technically straightforward and involves temporarily removal of a large section of the cranium following severe traumatic brain injury in order to accommodate acute brain swelling. In the past it was used as a salvage procedure when all other medical treatment had failed and the patient was thought likely to die without surgery. However, over the past two decades there has been a resurgence of interest. ${ }^{1-5} \mathrm{~A}$ recent randomised trial suggested that outcomes were worse for patients who had had an early decompressive craniectomy for diffuse traumatic brain injury than for those patients who received standard medical treatment. ${ }^{6}$ However, it emerged that the patients who received a decompressive craniectomy had a more severe traumatic brain injury and when this was corrected for there was no significant difference between the two groups. This in itself is an important finding because it reinforces the fact that the procedure should be performed not to reduce secondary brain injury and improve outcome but rather as a life-saving or rescue procedure where the patient is thought otherwise likely to die. A number of studies have shown that in these circumstances the procedure can lower the intracranial pressure and a significant number of patients may achieve a good functional recovery. Unfortunately, for some patients the primary brain injury is so severe that while the procedure is life saving, the neurological recovery is poor and they remain severely disabled. ${ }^{3-5}$ The degree to which that outcome is acceptable to those patients is difficult to establish but there has to come a point when careful consideration must be given to not surgically intervening because the most likely outcome would be unacceptable to the person on whom the procedure would be performed.

Until recently the difficulty has always been how to accurately assess the severity of cerebral injury and thereby provide reliable information about the most likely clinical outcome following decompressive surgery. The CRASH (Corticosteroid Randomisation After Significant Head injury) collaborators' outcome prediction model has gone some way to address this problem. ${ }^{8}$ It is been developed from the data collected on the 10000 patients in the CRASH study that investigated whether or not steroids were beneficial for patients with traumatic brain injury. While the results of the trial were negative the large amount of clinical data allowed investigators to combine the well-known prognostic indicators of age, initial Glasgow coma score, pupillary reaction, extracranial injuries and radiological appearances and establish a web prediction model that has been internally and externally validated in both high- and low-income countries. The model provides a percentage risk of an unfavourable outcome (defined by the Glasgow Outcome Scale of severely disabled, vegetative or dead) at 6 months' follow-up after traumatic brain injury.

In a recently published study comparing the predicted outcome with observed outcome in a cohort of 147 patients who had had a decompressive craniectomy for severe traumatic brain injury, it was shown that the prediction of an unfavourable outcome can serve as a surrogate index of injury severity. A prediction of an unfavourable outcome (or index of injury severity) $>80 \%$ means that the most likely observed outcome at 
18 months' follow-up would be severe disability with most survivors completely dependent. ${ }^{9}$ This has significant healthcare resource implications and therefore motivates the current discussion of the rule of rescue in this context.

The aim of this study was to compare the long-term healthcare requirements between two groups of patients:

1. Those with a predicted risk of an unfavourable outcome of $<80 \%$.

2. Those with a predicted risk of an unfavourable outcome of $>80 \%$.

The ethical issues arising from application of the rule of rescue can then be discussed in the light of real data.

\section{METHOD}

After obtaining approval from the hospital ethics committee we reviewed data from a previous study that reported on patients who had had a decompressive craniectomy between the years 2004 and 2008. ${ }^{9}$ The study was expanded to include those patients operated on in the year 2009 and focused specifically on the designation of the patients during the 18 months following the acute admission. The admission data were entered into the webbased prediction model established by the CRASH collaborators. ${ }^{8}$

A comparison was made between those patients who had a $>80 \%$ predicted risk of an unfavourable outcome and those who had a lower than $80 \%$ predicted risk

Specific note was made of:

1. length of stay in intensive care;

2. length of stay in the acute care hospital;

3. discharge designation and length of stay in either the rehabilitation facility, long-term nursing facility or home;

4. designation at 18 months;

5. outcome at 18 months.

\section{Statistical analysis}

The outcomes of patients with a predicted-risk of unfavourable neurological outcome $>80 \%$ were compared with patients with a lower predicted risk of unfavourable outcome ( $<80 \%)$. Categorical and continuous variables (with skewed distributions) were compared by $\chi^{2}$ and Mann-Whitney test, respectively. All statistical analyses were performed by SPSS for Windows (V.18.0 2009) and a $p$ value $<0.05$ was regarded as significant.

\section{RESULTS}

A total of 2532 adult and paediatric patients with neurotrauma were admitted to the two adult neurotrauma centres and paediatric hospital between 2004 and 2009 in Western Australia. Among a total of 2189 adult patients with neurotrauma admitted during the study period, 164 patients required either unilateral $(n=79)$ or bilateral $(n=85)$ decompressive craniectomy.

Among the whole cohort, at 18 months' follow-up: 65 patients had achieved a good outcome, 25 were moderately disabled, 31 were severely disabled, 5 were in a permanent vegetative state and 29 had died. On nine patients 18 month outcome was not available. Comparison of the resource requirements between those patients with a $<80 \%$ predicted risk of an unfavourable outcome and those with a $>80 \%$ predicted risk revealed significant differences (table 1).

Among the 43 patients with a predicted risk $>80 \%$, of the 24 patients who survived only three $(12.5 \%)$ patients had a favourable (Glasgow Outcome Scale good outcome or moderate disability) outcome. However, while they were independent all three remained moderately disabled. The remaining 21 survivors (49\%) were either severely disabled or in a vegetative state (table 2 ).

Among the 121 patients with a predicted risk $<80 \%, 102$ $(83 \%)$ had returned home. Only seven $(6 \%)$ required nursing home care and one patient remained in rehabilitation.

\section{DISCUSSION}

The rule of rescue described is derived from Jonsen ${ }^{10}$ and can be defined as "the injunction to rescue identifiable individuals in immediate peril regardless of cost". ${ }^{11}$ It can be interpreted either as a human proclivity or an ethical imperative. ${ }^{12}$ The classic examples are heroic searches for a sailor lost at sea or daring attempts to rescue someone in a burning building. In such cases while the chances of success may be small and the either the cost to the community or the risk to those attempting the rescue is extremely high, the psychological and moral imperatives are difficult to resist. This rescue morality spills over into medical care and describes the ethical imperative to save an individual life even when the money and resources might be more efficiently used to prevent deaths in the wider community. ${ }^{10} 11$

Within any healthcare system, if saving lives is considered to be of over-riding importance it is not difficult to invoke and justify the rule of rescue as a moral argument when considering decompressive craniectomy for patients with a severe traumatic brain injury. The patient meets salient criteria in that first, it is needed to avoid imminent loss of life and second, it increases

Table 1 Comparison of designation at 18 months after decompressive craniectomy between patients with a prediction of an unfavourable outcome of $<80 \%$ and those with a prediction of $>80 \%$

\begin{tabular}{|c|c|c|c|}
\hline \multirow[b]{2}{*}{ Glasgow Outcome Scale, n (\%) } & \multicolumn{2}{|c|}{ Prediction of an unfavourable outcome } & \multirow[b]{2}{*}{ p Value $\uparrow$} \\
\hline & $>80 \%(n=43)$ & $<80 \%(\mathrm{n}=121)$ & \\
\hline ICU stay*, days (SD, IQR) & $13(5,10-16)$ & $12(6,9-15)$ & 0.334 \\
\hline Acute hospital ward stay*, days (SD, IQR) & $120(81,55-186)$ & $43(41,19-50)$ & 0.001 \\
\hline $\begin{array}{l}\text { Rehabilitation or nursing home stay after } \\
\text { acute hospital stay*, days (SD, IQR) }\end{array}$ & $316(150,167-456)$ & $72(102,11-100)$ & 0.001 \\
\hline $\begin{array}{l}\text { Total stay in hospital rehabilitation*, nursing } \\
\text { home, days (SD, IQR) }\end{array}$ & $449(162,294-548)$ & $127(133,46-160)$ & 0.001 \\
\hline \multicolumn{4}{|l|}{ Destination at 18 months, $\mathrm{n}(\%)$} \\
\hline Dead & $18(42)$ & $11(8)$ & 0.001 \\
\hline Nursing home & $19(44)$ & $7(6)$ & \\
\hline Rehabilitation & $0(0)$ & $1(1)$ & \\
\hline Home & $6(14)$ & $102(83)$ & \\
\hline
\end{tabular}


Table 2 Comparison of observed outcome at 18 months after decompressive craniectomy between patients with a prediction of an unfavourable outcome of $<80 \%$ and those with a prediction of $>80 \%$

\begin{tabular}{|c|c|c|}
\hline \multirow[b]{2}{*}{ Glasgow outcome Scale, n (\%) } & \multicolumn{2}{|c|}{ Prediction of an unfavourable outcome } \\
\hline & $>80 \%(n=42)$ & $<80 \%(n=113)$ \\
\hline Good outcome (back to work/study) & $0(0)$ & $65(54)$ \\
\hline Moderately disabled (independent but unable work/study) & $3(7)$ & $22(18)$ \\
\hline Severely disabled (fully dependent) & $17(40)$ & $14(12)$ \\
\hline Vegetative (unaware of surroundings) & $4(9)$ & $1(1)$ \\
\hline Dead & $18(42)$ & $11(9)$ \\
\hline
\end{tabular}

life expectancy. What remains unclear is whether it results in a significant improvement in quality of life. ${ }^{11}$ It is hard not to offer rescue when we begin with the view that each person's desire to survive should be regarded as of equal importance, irrespective of the perceived quality and expected duration of life. ${ }^{13} 14$ However, the ethical problem is made pressing when, by giving absolute priority to preserving life, we seriously prejudice resource availability for other patients as yet unidentified. ${ }^{11} 15$ There has to come a point when a traumatic brain injury is so severe that the outcome would probably be unacceptable to the person on whom the procedure would be performed and also the long-term cost to the community might be greater than the benefit provided. ${ }^{16} 17$ The considerations here are not only financial but also personal and ethical and they require us to exercise well-considered judgement about our actions. ${ }^{18}$

In the first instance there is the difficulty in predicting outcome and thus considering the long-term implications of lifesaving but non-restorative surgical intervention. Second, there is the juxtaposition of the psychological and ethical imperative people feel to rescue individuals and finally there are the broader moral issues regarding the social utility of providing care for the most vulnerable members of the community.

\section{Outcome prediction and long-term outcome}

When obtaining consent to proceed with a decompressive craniectomy for a severe head injury the acute care teams need to try to take account of what a patient's decision might be if that patient could be asked. ${ }^{17} 18$ Unfortunately, discussions with surrogate decision-makers are often dichotomised into life or death and if this is the case a further outcome category will not be acknowledged. That category is long-term survival with severe disability. This has previously been characterised as the RUB, an acronym for the 'risk of unacceptable badness' and describes a situation that the patient, were it possible that they could be asked, would find unacceptable. ${ }^{17}$

Most discussions in acute care are fraught with emotion and commonly result in statements such as "the family want everything done". This can be interpreted in a number of ways not least of which is a plea for the doctors "to do their best" and it is here that an opportunity may present itself to expand the discussion. While obviously debatable, there has to come a point where the 'best' treatment may be to consider not intervening and to have the long and difficult discussion with the family and perhaps also with colleagues who may question the lack of 'lifesaving' decompressive surgery.

If there is a prediction of an unfavourable outcome of $>80 \%$, a surviving patient is likely to remain severely disabled. A mathematical model, while limited, does provide an accurate index of injury severity and may be useful in providing cause to pause and consider the long-term implications of life-saving but non-restorative surgical intervention.

\section{The rule of rescue}

Realistically, for a young person with a severe head injury and a prediction of an unfavourable outcome of $<80 \%$, it would be difficult not to invoke the rule of rescue and proceed with a decompressive craniectomy, despite the possibility of long disability and the subsequent long-term resource implications. However, once the outcome prediction exceeds $80 \%$ the probable outcome if the patient survives is severe disability and long-term reliance on expensive medical and nursing resources. The issues here are not only what the patient would find acceptable but how much value the society places on human life and at what cost. The considerable debate regarding cost containment and rationing of health resources ${ }^{19-21}$ can be taken to imply that the cost of a health intervention provided to an individual should be no more than the life and quality of life that would be gained by using the resources elsewhere. ${ }^{22}$ This adds into the equation not just the good of caring for each and every individual ${ }^{12}{ }^{22}$ but also some measure of health benefit realistically expected from the treatment. 2324

The fundamental difficulty, as demonstrated by the Oregon experience, is producing a cost-effectiveness analysis that is both socially and politically acceptable given the psychological imperative to rescue. ${ }^{25}$

Further considerations are the utilitarian theories of value. These acknowledge that resources are scarce and must be allocated to ensure that the overall performance of a healthcare system is maximised. An egalitarian assumption adds a further constraint of fairness to try and ensure universal access to adequate healthcare. From this standpoint it is difficult to justify life-saving intervention when the probable outcome is severe disability with that individual reliant on long-term medical and nursing care and creating opportunity costs for others who would otherwise be able to be treated for various needs. However, this position fails to recognise the considerable social value in caring for those most in need especially if this is undiluted by considerations of cost. ${ }^{20}$ While attempts to preserve life at any cost may be incompatible with utilitarian resource allocation, conveying the message that life is precious and worth a great deal of effort to preserve, can be a source of social utility. People obtain benefit from the belief that they are living in a caring and humane society and heroic attempts to save a young person's life serves to reinforce this belief. ${ }^{22}$ This can provide a feeling of security knowing that one lives in a compassionate society which cares for the needs of each constituent member and where those in most desperate need will not be ignored merely on the basis of resource allocation. ${ }^{20}$

The difficulty comes when it is no longer clear that we are doing the best for the individual by our attempt to rescue-as is the cases where we save them to be survivors living in a state they would regard as unacceptably bad. This exerts intense ethical pressure at the point at which the utilitarian value of demonstrating compassion fails to justify the utilitarian cost of 
poorly allocated resources. Even at this stage any strategy aimed at rationalising healthcare resources must take into account what is acceptable to society. ${ }^{11}$ There is an inescapable fact about human nature that will always favour caring for, or 'rescuing' those vulnerable individuals who are most in need despite the utilitarian rationality that is implicit in a cost-benefit analysis.

\section{CONCLUSION}

There is a strong psychological and ethical imperative to save a life of a young person with a severe head injury. In the acute setting it is difficult to support a utilitarian argument that seems to show that the money and resources might be better spent preventing death and disease in the larger community. It can equally be argued that by being aware that every attempt will be made to save the life of a severely injured young person, those in the community at large are provided with social utility and will be made to feel more secure knowing that they are part of a caring society. However, that security is threatened if the rescue system is seen to be a juggernaut that is insensitive to the way people actually value their lives. What we have shown is that in the acute neurotrauma outcome cannot be dichotomised into simply life or death and our intentions cannot be rationalised on a mere cost-benefit analysis. There has to come a point where the strong psychological imperative to save a life and the social value of showing compassion must be resisted and the moral imperative must be accepted. If the most likely outcome would be unacceptable to the person on whom the procedure would be performed then the social utility implicit in the rule of rescue will not be justified. In such a case if a surgeon chooses to act on the psychological imperative they must accept that they could not reasonably assume that they would obtain consent from the patient for the operation (were that possible) and would have to justify acting on their own judgement, not only against the most likely wishes of the patient but also against their moral responsibility to the community to exercise fair equitable allocation of the resources at their disposal.

Competing interests None.

Ethics approval This study was approved by Sir Charles Gairdner Hospital human research ethics committee.

Contributors All authors contributed equally.

Provenance and peer review Not commissioned; externally peer reviewed.

\section{REFERENCES}

1. Aarabi B, Hesdorffer DC, Ahn ES, et al. Outcome following decompressive craniectomy for malignant swelling due to severe head injury. $J$ Neurosurg 2006;104:469-79.

2. Albanèse $\mathbf{J}$, Leone $\mathrm{M}$, Alliez $\mathbf{J R}$, et al. Decompressive craniectomy for severe traumatic brain injury: Evaluation of the effects at one year. Crit Care Med 2003;31:2535-8

3. Guerra WK, Gaab MR, Dietz $\mathrm{H}$, et al. Surgical decompression for traumatic brain swelling: indications and results. J Neurosurg 1999;90:187-96.

4. Honeybul S, Ho KM, Lind CR, et al. The retrospective application of a prediction model to patients who have had a decompressive craniectomy for trauma. $J$ Neurotrauma 2009;26:2179-83.

5. Polin RS, Shaffrey ME, Bogaev CA, et al. Decompressive bifrontal craniectomy in the treatment of severe refractory posttraumatic cerebral edema. Neurosurgery 1997;41:84-94.

6. Cooper DJ, Rosenfeld JV, Murray L, et al; the DECRA Trial Investigators and the Australian and New Zealand Intensive Care Society Clinical Trials Group. Decompressive craniectomy in diffuse traumatic brain injury. $N$ Engl J Med 2011;364:1493-502.

7. Gillett GR, Honeybul S, Ho KM, et al. Neurotrauma and the RUB: where tragedy meets ethics and science. J Med Ethics 2010;36:727-30.

8. Perel P, Arango M, Clayton T, et al. Predicting outcome after brain injury: Practical prognostic models based on a large cohort of international patients. BMJ 2008:23:425-9.

9. Honeybul S, Ho KM, Lind CR, et al. Observed versus predicted outcome for decompressive craniectomy: a population-based study. J Neurotrauma 2010;27:1225-32.

10. Jonsen AR. Bentham in a box: technology assessment and health care allocation. Law Med Health Care 1986;14:172-4.

11. Cookson R, McCabe C, Tsuchiya A. Public healthcare resource allocation and the Rule of Rescue. J Med Ethics 2008;34:540-4.

12. Sheehan MJ. Resources and the rule of rescue. J Appl Philos 2007;24.4:352-66

13. Harris J. The Value of Life. London and New York: Routledge, 1985.

14. Harris J. QALYfying the value of life. J Med Ethics 1987;13:117-23

15. Fuchs VR. The "rationing" of medical care. N Eng/ J Med 1984;13:1572-3.

16. Gillett GR. Bioethics in the Clinic. Baltimore: Johns Hopkins University Press, 2004.

17. Gillett GR. The RUB. The risk of unacceptable badness. N Z Med J 2001; 27:188-9.

18. Gillett GR. Sanctity of life, a sense of life, and good endings. QUT Law and Justice Journal 2006;6.2:243-52.

19. Bochner F, Martin ED, Burgess NG, et al. How can hospitals ration drugs? Drug rationing in a teaching hospital: a method to assign priorities. Drug Committee of the Royal Adelaide Hospital. BMJ 1994;2:901-5.

20. Cookson R, Dolan P. Principles of justice in health care rationing. J Med Ethics 2000;26:323-9.

21. Relman AS. Is rationing inevitable? N Engl J Med 1990;21:1809-10.

22. Hope T. Rationing and life-saving treatments: should identifiable patients have higher priority? J Med Ethics 2001;27:179-85.

23. Daniels N. Why saying no to patients in the United States is so hard. Cost containment, justice, and provider autonomy. N Engl J Med 1986;22:1380-3.

24. Kaplan RM. The Hippocratic Predicament: Affordability, Access, and Accountability in American Medicine. San Diego, Calif: Academic Press, 1993.

25. Hadorn DC. Setting health care priorities in Oregon. Cost-effectiveness meets the rule of rescue. JAMA 1991;1:2218-25. 